\title{
Moradas de encante e vizinhos do fundo: habitação e socialidades interespecíficas no noroeste amazônico
}

\author{
Luiz Augusto Sousa Nascimento ${ }^{1}$ \\ Instituto Federal do Maranhão
}

Resumo: Pesquisa etnográfica foi realizada no noroeste amazônico junto as populações indígenas multiétnicas habitantes das calhas dos rios Padauiri e Preto afluentes da margem esquerda do rio Negro. O presente texto de caráter descritivo e analítico, percorre pelas narrativas explicativas elaboradas, reproduzidas e ou reificadas pelos indígenas rionegrinos. Analiticamente, dialogamos com as concepções do perspectivismo ameríndio para traçar conexões ao multinaturalismo e trazer para o debate algumas noções locais, tais como encante e encantado, gentes e donos, vizinhos e inimizades que possam contribuir para uma síntese sobre vizinhança e socialidades interespecíficas entre "gentes" no contexto do noroeste amazônico.

Palavras-chave: multinaturalismo; perspectivismo; sociabilidades interespecíficas. 


\title{
Enchanting addresses and background neighbors: housing and interspecific socialities in the northwest of the Amazon
}

\begin{abstract}
Ethnographic research was carried out in the northwest of the Amazon with the multiethnic indigenous populations inhabiting the gutters of the Padauiri and Preto rivers, tributaries of the left bank of the Negro river. The present text of a descriptive and analytical character, goes through the explanatory narratives elaborated, reproduced or reified by the indigenous Rionegrinos. Analytically, we dialogue with the conceptions of Amerindian perspectivism to draw connections to multinaturalism and bring to the debate some local notions, such as enchanted and enchanted, people and owners, neighbors and enmities that can contribute to a synthesis about neighborhood and interspecific socialities between "people" In the context of the northwestern Amazon.
\end{abstract}

Keywords: multinaturalism; perspectivism; interspecific socialities.

\section{Casas de el encante y vecinos de fondo: vivienda y socialidades interespecíficas en el noroeste de la Amazonía}

\begin{abstract}
Resumen: La investigación etnográfica se realizó en el noroeste de la Amazonía con las poblaciones indígenas multiétnicas que habitan los cauces de los ríos $\mathrm{Pa}$ dauiri y Preto, afluentes de la margen izquierda del río Negro. El presente texto de carácter descriptivo y analítico, pasa por las narrativas explicativas elaboradas, reproducidas o reificadas por los indígenas rionegrinos. Analíticamente, dialogamos con las concepciones del perspectivismo amerindio para establecer conexiones con el multinaturalismo y traer al debate algunas nociones locales, como encante y encantados, gente y donos, vecinos y enemistades que pueden contribuir a una síntesis sobre el vecindario y las socialidades interespecíficas entre "gentes" en el contexto de la Amazonía noroccidental.
\end{abstract}

Palabras clave: multinaturalismo; perspectivismo; sociabilidad interespecíficas. 
A região do noroeste amazônico constitui um espaço rico em diversidade socioambiental. O rio Negro, o grande eixo fluvial da região, percorre, desde sua nascente na região colombiana até sua foz em Manaus, mais de mil e setecentos quilômetros. No seu curso principal e afluentes situam-se mais de quinhentas comunidades indígenas, com seus territórios próprios e marcante autonomia política, congregadas em dezenas de organizações e associações indígenas ${ }^{2}$ ". As comunidades na sua grande maioria são multiétnicas, pois a região é habitada por vinte e três povos indígenas falantes de dezesseis línguas vinculadas a quatro famílias linguísticas 3 (Tukano Oriental; Aruak; Naduhuo e Yanomami). A esses fatores associam-se ainda outras peculiaridades como, por exemplo, a exogamia linguística, a virilocalidade como sistema de residência pós-marital, além de alguns temas sociocosmológicos amplamente disseminados, como o motivo mítico da cobra-canoa e os rituais do Jurupari; Umuri Ñehku (avô do universo); Uétsu (pai do paricá e caapi); Kuwai (herói mítico entre os aruak) entre outros e alguns cerimoniais transversais, como o Dabukuri, o Kariamã e os cantos de caapi4.

Do ponto de vista ambiental, a bacia do rio Negro abriga algumas espécies endêmicas de importância vital para a vida dos indígenas e para a economia local, por exemplo, o Chicirodon axelrodi (cardinal), peixe ornamental raríssimo com grande demanda para exportação e a Leopoldina piasaba (palmeira de piaçaba), cujo extrativismo da sua fibra é extraída pelos indígenas e negociada pelo viés do regime de aviamento muito comum na Amazônia. O regime de aviamento se baseia numa relação assimétrica e hierárquica entre sujeição, exploração e "proteção"5.

Desde a expedição do explorador espanhol Francisco Orellana em 1542, a presença de outsiders de diversas nacionalidades na região foi constante e muita das vezes, nefasta para as populações indígenas locais (guerras, escravização, doenças contagiosas e evangelização cristã). O território passou por vários processos históricos de gestão colonial, ocupação militar, implantação de missões cristãs e vilas, que, no século XX, deram origem aos centros urbanos da região, como as cidades de Barcelos, Santa Izabel do Rio Negro e São Gabriel da Cachoeira. Todos esses processos causaram grandes impactos sobre os povos nativos locais. As pressões endógenas advindas da presença colonial, levaram alguns povos indígenas a utilizar estratégias variadas de aproximação aos brancos, por meio de ações díspares e paradoxais, de aproximações táticas às rebeliões e afastamen$\operatorname{tos}^{6}$.

Essas estratégias tiveram efeitos diferentes. Os povos situados no baixo e médio rio Negro, primeiramente atingidos pela colonização no século XVIII, registrados nas fontes por exemplo, os autodenominados pelos colonos de Baré, Manáo e os Passe, pagaram pela estratégia do enfrentamento, pois seus principais líderes foram dizimados e parte da população nativa foi incorporada às vilas co-

\footnotetext{
2 Sobre chefia tradicional, movimento indígena e política no rio Negro, ver Aline IUBEL (2014; 2018) e Renato SOARES (2012).

3 Com exceção dos Yanomami, os outros povos convergem em suas sociocosmológicas.

4 Sobre alguns cerimoniais rionegrinos, ver BARROS (2012), sobre o Kariamã ver MAIA FIGUEIREDO (2015).

5 Sobre o regime de aviamento e economia no rio Negro ver NASCIMENTO (2017, 2013) e MEIRA (1993, 2017).

${ }^{6}$ Sobre a história de colonização no rio Negro, ver (WRIGHT, 1992) e (ANDRELLO, 2004).
} 
loniais, resultando na suspensão do uso da língua nativa e da proibição dos principais rituais de iniciação e de sociabilidades. Os povos que permaneceram nas áreas mais distantes, nas cabeceiras, enfrentaram mais tarde "perseguição civilizatória" dos missionários, deixando suas malocas e passando a habitar as circunvizinhanças dos internatos cristãos que foram sendo erguidos na floresta.

Os povos rionegrinos souberam introduzir novos arranjos sem se desvincular das hierarquias tradicionais e do território como espaço coletivo memorial. No entanto, no momento atual, com o crescimento das cidades, novos efeitos passam a surgir. Um deles, diz respeito a uma aparente inversão quanto aos valores associados às posições daqueles que vivem nas cabeceiras dos rios:

\begin{abstract}
Agora o nosso povo tá descendo o rio ao invés de subir. Os velhos diziam que antigamente morar na cabeceira era coisa de gente grande, isso não era porque estava se escondendo dos inimigos não. Tinha que ter muita sabedoria para morar nas cabeceiras. Agora moço! Nós queremos é descer o rio, ficar próximo mesmo da boca. Eu já morei em cima, lá na cabeça do Padauiri, mas agora quero ficar por aqui mesmo, perto das coisas. Eu sou filha de índio tukano legítimo, a família do meu pai era de uma família [clã] de líder mesmo, aquele da ponta. A gente tá aqui, mas todos sabem que somos filhos de gente da cabeceira. (Irene Souza Tukano, comunidade de Acuacu, outubro de 2010)
\end{abstract}

Trata-se, portanto, de um modus vivendi atribuído ao tempo dos antigos, no qual os clãs herdariam posições hierárquicas de acordo com sua origem mítica. Isso garantiria o direito de ocupar as cabeceiras dos principais rios e estabelecer relações sociais adequadas com outros clãs. Face esse pano de fundo, focalizaremos aqui um outro aspecto das relações que envolvem a rede fluvial da região: vamos atentar para as "moradas de encante", os "vizinhos do fundo das águas", com quem os seres humanos mantêm complexas e ambíguas relações, porém igualmente marcadas por atração e perigos, desejos e repugnância. Com o intento de lançar luz sob essas questões, o presente texto, está organizado em três seções: a primeira, resgata o contexto da pesquisa e as múltiplas formas de moradias (malocas e comunidades), bem como as diversas "gentes" e suas vizinhanças. A segunda se concentra na cidade dos encantes vista pelo prisma dos humanos, resgatadas pelo viés das narrativas, elementos estruturantes aos atos motivadores de socialidades interespecíficas e os processos relacionais e, por fim, uma abordagem sobre as visitas dos vizinhos do fundo às comunidades e as idiossincrasias dos trâmites de vínculos entre mundos fazendo uma conexão a algumas nuances do perspectivismo ameríndio.

\title{
“Gente é gente em todo lugar": moradias, vizinhanças e socialidades
}

A região do noroeste amazônico impactada pela presença colonial, deixou ruir alguns elementos estruturais da organização social dos indígenas. As malocas, consideradas moradas da sabedoria, ventre de criação e proteção é considerada pelos indígenas como espaço de orientação para vida. Elas foram assoladas pelo empreendimento colonial e mesmo diante desse ímpeto, os espaços de moradias no rio Negro mantiveram o vínculo às bases sociocosmológicas. Embora o sistema de moradias seja multiforme e plurilocal, atualmente predominam os sistemas de comunidades, que foram impostas pelo "processo civilizatório", no entanto, se conservou muito dos arranjos e modus de orientação das malocas, bem como prevalece o ordenamento sócio-espacial configurado sob a égide das hierarquias frátricas. Nesse sentido, poderemos considerar as atuais comunidades como um espelho das antigas malocas? Não, de maneira alguma, no entanto, na 
opacidade da imagem da maloca se pode perceber através de uma refração prismática, feixes se incidindo aos eixos da transmissão de conhecimentos, das socialidades e dos espaços de similaridades entre "gentes".

Muitos autores da antropologia vêm debatendo a questão da concepção da noção de comunidade. Para o nosso caso, as formulações de três autores parecem particularmente relevantes e complementares ao nosso intento: APPADURAI (2008), OVERING (1999) e LASMAR (2005). APPADURAI (2008) considera a comunidade como uma relação social espontânea que se caracteriza por ligações recíprocas de afeição e parentesco no interior de uma tradição comum. OVERING (1999), em pesquisa entre os Piaroa na Amazônia venezuelana, desenvolveu a ideia de "comunidade de similares" considerando os processos de vida comum ou homogeneidade comunitária, o que torna os membros de uma comunidade progressivamente similares uns aos outros mantendo uma homogeneidade material constituída pela mutualidade de vida em comum. Para OVERING (Ibid.), os membros de uma comunidade vão se tornando da mesma natureza onde são gerados, não somente por laços de parentesco, mas por um conjunto maior de partilhas e convivialidades, substâncias, habilidades, no intuito de alcançar uma melhor qualidade de vida para todos. Na mesma direção, LASMAR (2005) sugere que a comunidade é considerada como um grupo local constituído por parentes consubstanciais. Para os indígenas rionegrinos, a comunidade tende a reunir um pouco do que foi apresentado pelos autores acima, no entanto, comunidade é vista como morada e, morada implica juntar gentes em perspectivas relacionais diferentes e paradoxais, por exemplo, os amigos e inimigos, predadores e presas, desejáveis e indesejáveis, parentes e não parentes. Esses correlatos são centrais para compreender espaços de moradias, vizinhanças e socialidades no âmbito do noroeste amazônico.

Vista por esse ângulo, a comunidade é percebida como um espaço amplo de socialidades entre gentes de diferentes ordens que habitam o cosmos (humanos e extra-humanos; gente-do-fundo e gente-de-cima; gente-peixe e gente-onça; encantados, os santos; patrões, fregueses entre outros). Na comunidade "gentes" se encontram nas mais variadas ocasiões e formas e são partes integrantes dos principais ritos de iniciação, dos cerimoniais de agregação justapostos de maneiras complementares. A comunidade exerce, assim, uma força de atração sobre vários agentes com poder de agenciamento.

[...] gente é gente em todo lugar, e não é possível que pessoas se comportem tão mal
assim, a não ser que tenham sido ofendidas ou mesmo carregar a inveja de outra
gente. Ninguém mexe com gente do fundo só por mexer e eles não entram em nossas
casas sem motivo ou sem ninguém chamar. Tem gente que vivem implicando com
gente-do-fundo, agredindo e extraviando as coisinhas deles, sabe! Não se pode mali-
nar demais, estão malinando tanto e isso desperta o desejo dos bichos [gente-do-
fundo] eles se ofendem e vêm malinar com a gente também. A resposta: eles estão
levando os nossos para o fundo e ainda entram em nossas casas, mexem com quem
tem sangue frio, brinca, bebe e vai embora. Já estão acostumados, ninguém nem
birra mais, a gente sabe que tudo é assim. A comunidade é comunidade desse jeito,
vivemos com todos que a nossa cabeça [alembra]. Essas gentes não saem da nossa
vida”. Vivem aqui desde os tempos dos mais antigos. (Alberto Jesus Baré, Rio Preto,
julho de 2013)

A maioria dos espaços onde se assentam as comunidades no médio rio Negro é considerado um lugar de encante e muitos desses espaços estão localizados em cima de cidades encantadas. Na região é consensual a ideia das cidades encantadas. De maneira diversificada, as narrativas coadunam em sinédoque dos tempos primordiais aos "tempos dos patrões7". 
As comunidades localizadas nas calhas dos rios Padauiri e Preto (Campina e Tapera) apresentam uma visão privilegiada devido a sua localização sócio-espacial, pois se posicionam no encontro entre rios e estão assentadas em área de campina, que sobressaem os solos arenosos que se estendem em grandes extensões formando bancos de areias e belíssimas praias de rios. No Padauiri e Preto navegam todos os tipos de "gente": patrões, fregueses, regatões, Yanomami8, gente do governo, missionários, turistas (brasileiros e estrangeiros), pesquisadores, gente-do-fundo, entre outros, fato que torna a região, um espaço privilegiado para a observação.

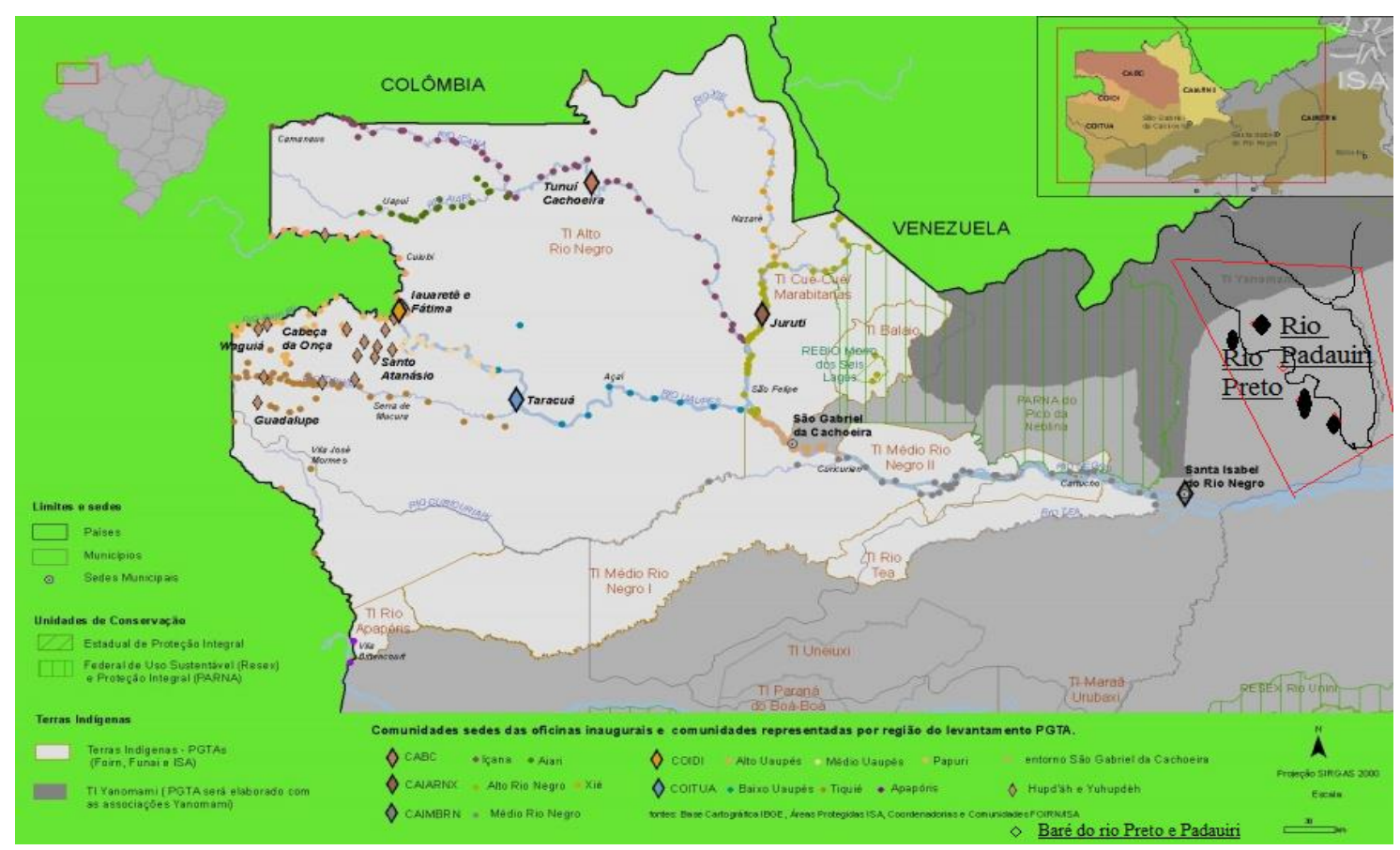

Fig. 1 - Região do noroeste amazônico. Em destaque as calhas dos rios Padauiri e Preto: Fonte Nascimento (2017)

Entre as comunidades de Campina do Rio Preto e Tapera, onde realizei a etnografia, observa-se algumas peculiaridades, tais como as histórias de ocupação e fundação, a organização social, as unidades de produção e consumo e alguns elementos idiossincráticos que fazem parte do contexto sociológico e de ocupação de ambos os rios (Padauiri e Preto), tais como a "poligamia encantada" e o campo relacional que os moradores estabelecem com as cidades encantadas e com patrões encantados. Foi nas duas comunidades que descobrir a plasticidade das vizinhanças, o trânsito de mobilidade impermeável que ultrapassa a esfera da subjetividade dos sujeitos. Nesse contexto, procuramos navegar pelas correntes fluviais que nos guiassem em direção as cidades encantadas e pudessem nos estabelecer o encontro com outros mundos e com suas "gentes".

\section{As cidades Encantadas}

Numa manhã de novembro de 2013, debaixo de uma chuva rala, descia o rio Preto abordo de uma canoa rabeta, acompanhado de três homens baré; duas mulheres da etnia Baniwa e um cachorro esquelético. $O$ objetivo era coletar manga na localidade situada nas proximidades da comunidade de Thomar, na margem

${ }^{8}$ Destaco os Yanomami pelo fato de os Baré do rio Preto considerá-los como outro tipo de gente. 
direita do curso médio do rio Negro. Chegando na comunidade de Thomar, fiquei deslumbrado pela beleza do lugar, pelo estado das edificações erguidas outrora, pois, mesmo em ruínas, insistiam em permanecer de pé como testemunhas dos tempos áureos da economia dos seringais na região. Não entendia o porquê de "gentes" terem abandonado aquela comunidade tão bem situada, cheia de recursos naturais e uma bela paisagem. De acordo com SAMPAIO (2010), Thomar é uma das comunidades mais antigas da região e foi palco de uma das batalhas mais intensa ocorrida na bacia do rio Negro, conhecida como "Formidável Motim", que ocorreu em 1757 entre indígenas de diversas etnias e colonos portugueses. Esta batalha colocou em xeque boa parte dos assentamentos portugueses na região do Médio Rio Negro.

Thomar foi comunidade próspera durante muito tempo, com edificações de casas que fugiam a regra dos padrões locais; no entanto, antes do término da economia sustentada pelos seringais, havia sido reduzida a ruínas. Várias tentativas de reocupação foram feitas, porém, como enfatizou o ancião baré Antônio Buyawaçu, "como morada de gente Thomar não se sustenta". Perguntei por que, e ele respondeu-me: - "por causa dos encantados". Mas não tem encantado em todo o rio Negro? Perguntei para Buyawaçu, que retrucou: “- sim, mas aqui eles não souberam lidar com essas coisas. Aqui tem uma cidade encantada no fundo e você tem que saber lidar com ela. Veja lá em Campina! Campina está assentada em cima de uma cidade encantada, mas meu sogro [Caetano de Jesus] soube fazer as coisas, então ele soube amansar os bichos-do-fundo. Dizem por aí que um dia Campina vai acabar igualzinha a Thomar, porque cidade de gente não pode ser construída em cima de cidade dos encantados. Mas eu não acredito isso não, quem diz isso é o povo da Ilha [Nova Vida grupo de dissidentes de Campinas do Rio Preto] que também tem inveja de nós. Os encantes da cidade de Campina já estão acostumados com o povo do rio Preto”. Ressaltou o ancião baré.

Foi a partir dessa conversa com Antônio Buyawaçu que me inteirei que abaixo da comunidade de Campina do Rio Preto, havia uma cidade encantada. Desde então, procurei observar a comunidade a partir da perspectiva dos seus moradores quanto a sua relação com as vizinhanças das cidades encantadas e com os encantes. Posteriormente, fui informado, que alguns moradores da comunidade realizaram contatos com os chefes do mundo-de-baixo, com a finalidade de tornar viável esta convivência. Mas o mais surpreendente é que, para tanto, o patriarca da comunidade de Campina, o ancião Caetano de Jesus Baré, veio a contrair ainda assim, uma aliança matrimonial com uma mulher encantada. A partir de então, os encantados solicitam frequentemente novas relações do mesmo tipo com o povo de Campina. Como ouvi muitas vezes:

\begin{abstract}
Os encantados gostam de visitar nós Baré, pois nós somos diferentes e sabemos labutar com os nossos vizinhos. Meu sogro conhecia isso tudo muito bem. Ele respeita todos e sabe que no fundo é um pouco parecido. Não se pode malina e judiar com eles [gente-do-fundo]. Ninguém gosta, sabe! Aqui nessa beira de rio todos sabem da sabedoria do meu sogro. Ele foi muito para o fundo [cidades-do-fundo]". (Antônio Buyawaçu, comunidade de Campina do Rio Preto, novembro de 2013)
\end{abstract}

Para os Baré do rio Preto, a "cidade encantada" se assemelha a Manaus, cheia de luzes, casas bem ornamentadas com mobílias e habitada por muita gente. É um "lugar onde se vê coisas estranhas" e se ouvem ruídos desconhecidos, parecidos com o ronco dos motores dos automóveis, muito embora se trate de ruídos de outros animais. A cidade encantada constitui juntamente a morada dos encantados, isto é, compreende todo o universo de "gente-do-fundo", que por sua vez possui um lugar central no pensamento dos indígenas do rio Negro, assumindo, 
no entanto, feições específicas de localidade para localidade. Por exemplo, os Baré que vivem em Manaus têm uma versão em relação à cidade encantada que difere em detalhes da dos Baré do rio Preto. Ao invés de afirmarem que a cidade encantada é parecida com Manaus, os Baré citadinos preferem fazer referência à cidade do Rio de Janeiro, como sendo a que mais tem semelhança com a cidade do fundo, devido as suas luzes, brilhos, serras, morros e o grande mar. As cidades encantadas possuem casas coloridas e bem edificadas, hospitais, centro para realização de festas, roças, entre outras estruturas físicas que existem no mundo de cima.

A cidade encantada, do ponto de vista dos Baré se constitui politicamente, obedecendo a uma ordem hierárquica: 1) cobra-grande; 2) o chefe dos botos e; 3) o chefe das raias9. Essas três "raças", como denominam os Baré, são seres muitos temidos pelos moradores de cima. Estes seres constituem a categoria de encantados, dotada de grande poder e capacidade de metamorfose. Eles costumam intervir nas relações dos humanos com os outros seres não aquáticos, por exemplo, os "bichos-das-matas" e os animais silvestres.

Os moradores das cidades encantadas são responsáveis pelo aparecimento de certas doenças que os Baré consideram como sendo um "encanto", um ataque de pequenas pedras e flechas (talas de buriti e bacaba), ambas invisíveis. Esses elementos provocam dores que indicam sinais de que alguma doença penetrou o corpo. Para estes males, somente o tratamento propiciado pelo benzedor tornase significativo e eficaz, consistindo, sobretudo, em benzimentos que têm o poder de "desmanchar" as flechas e pedras. Ao serem desmanchados, esses elementos saem do corpo da pessoa, ocasionando um alívio imediato. $\mathrm{O}$ benzimento é uma dentre várias práticas capazes de curar uma pessoa acometida por ataques de encantados.

Para os Baré do rio Preto, as investidas dos vizinhos encantados, bem como de certos animais "agourentos" e peçonhentos é percebida como sendo uma vingança pelas infrações humanas contra os moradores das cidades encantadas, sobretudo a não observância de certos cuidados, tais como matança em demasia de peixes e outros animais e o abate de fêmeas cujas crias ainda dependem dos cuidados da mãe. Estes atos podem provocar transformações profundas nas pessoas e levá-las a um "estado de encante". Esse estado só pode ser curado com os "remédios da mata" e através da ação de um benzedor ou pajé, os quais são os mediadores fundamentais nesse cenário perigoso de relações de sociabilidades entre "gentes". Como mencionado anteriormente, os benzimentos, aliados a outras práticas terapêuticas, constituem mecanismos de proteção e estão relacionados à domesticação e neutralização dos poderes ameaçadores dos vizinhos encantados e de outros seres da floresta.

Os ataques cometidos contra as pessoas da comunidade de Campina do Rio Preto são ordenados principalmente pelos chefes das cidades encantadas. Todavia, os moradores de Campina reconhecem que os chefes que comandam a cidade encantada, abaixo da comunidade, moram mesmo é no "rio grande"10", e os que estão no rio Preto e Padauiri são somente seus encarregados.

Aqui no rio Preto só tem encarregados, os fortes mesmos estão no rio Grande. Você já viu falar em arraia [raia] atacar a gente aqui? Não. Elas estão no rio Negro. Aqui

\footnotetext{
9 Para ÄRMEM (2001: 275), Los Padres de los peces son las anacondas y las rayas que viven en las profundidades de los ríos y las lagunas. De la misma manera, los tapires son los dueños de los animales frugívoros del bosque cuyas malocas son los salados.

${ }^{10}$ Os Baré possuem uma forte ligação mítica e simbólica com os rios que atravessam o noroeste do Estado do Amazonas. Nesse contexto, o rio Negro, reconhecido como o "rio maior" ou "rio grande", possui um lugar de destaque, como se depreende de uma narrativa que descreve acontecimentos da mitologia baré, relativos aos tempos da criação.
} 
só tem arraias daquelas pequeninas, as crias são quem andam por aqui juntos outros parceiros, mas as mães das arraias [raias] estão no rio Negro. No rio negro tem um lugar cheio desse bicho [raias]. Eles tomam de conta do rio Negro e mandam para os rios menores só os encarregados. É como patrão também, que tem seu lugar, mas gosta de mandar no lugar do outro e carrega um bocado de encarregados. É assim mesmo seu Augusto. O meu Neto quase morreu no rio Negro quando a gente passava pelo poço do Humaitá ${ }^{11}$. Uma arraia grande puxou nossa canoa para o fundo, elas queriam meu neto novinho. A gente tem que ter cuidado com os bichos do fundo, assim mesmo são os botos, mas tem boto que não malina". (Antônio Buyawaçu, comunidade de Campinas do Rio Preto, agosto de 2014)

Geralmente, as cidades encantadas estão localizadas em espaços considerados especiais por ser lugar de fartura, tais como poços, enseadas, grandes praias, lagos, nas proximidades de serra. REICHEL-DOLMATOFF (1990) enumera uma lista de espaços possíveis de localização de malocas invisíveis e habitação de encantados:

\begin{abstract}
Los pozos profundos que forman al pie de los raudales o de grandes rocas, se cree albergan 1as malocas subacuáticas del Dueño de los Peces; $y$, del mismo modo, las lagunas, cavernas, troncos huecos y otros puntos sobresalientes en el paisaje tienen sus dueños sobrenaturales. Lo mismo se puede decir de palmas o de árboles frutales, ya que todos esos seres sobrenaturales tienen sus chagras y malocas invisibles, interconectadas por una rede caminos y trochas. El paisaje entero se considera densamente ocupado por estas presencias fantasmales. (REICHEL-DOLMARTOFF, 1990: 23)
\end{abstract}

A comunidade de Campina do Rio Preto está assentada numa localidade predominantemente formada por uma vegetação de campinarana, composta por um solo alvo arenoso, dando uma beleza específica semelhante às praias do rio Negro. Os moradores de Campina se orgulham em dizer que moram numa comunidade que não vai ao "fundo" durante o período da enchente do rio, diferentemente das outras comunidades do curso do rio Preto e Padauiri que são inundadas durante a estação das chuvas. A posição privilegiada da comunidade de Campina é explicada, pelos moradores locais, como sendo uma área que é sustentada pela estrutura da cidade encantada. Eles afirmam que a cidade encantada existe há milhares de anos no rio Preto, quando eles tentam comprovar pelos achados de antigos objetos encontrados enterrados no interior de uma residência da comunidade. As peças encontradas foram uma espada de maçaranduba, uma canoa, um remo de madeira petrificado, restos de matapi e cesto, ambos tecidos de piaçaba, e uma grande quantidade de cacos de cerâmica. Todo esse material é considerado pelos moradores da comunidade como pertencentes aos moradores da cidade encantada. Os moradores mais antigos do rio Preto e Padauiri afirmam já ter visto ouro, mas não deixam ninguém tirar. A notícia da descoberta de um mineral reluzente se espalhou e não tardou para que aparecesse na comunidade um grupo de geólogos e garimpeiros solicitando permissão dos líderes para realizar pesquisa no entorno da área pertencente a comunidade. Os moradores mais velhos foram contra as pesquisas geológicas e não aceitaram, de maneira alguma, "mexer nas coisas dos encantados", pois se retirar o ouro de Campina, a terra apodreceria, a comunidade e suas gentes se tornariam invisíveis. Eles temem uma retaliação dos entes do fundo e, por isso, evitam qualquer intervenção neste sentido. Portanto, extrair ouro no rio Preto é uma atividade restritamente perigosa e esse ato salvaguarda os entes do fundo e protege a comunidade e suas gentes.

De maneira geral, os Baré contam que existe um movimento constante que emerge das cidades encantadas, porém nem todas as pessoas podem observar.

${ }^{11}$ Para os Baré do rio Preto, o poço do Humaitá, acima do sítio do mesmo nome é uma cidade dominada pelas raias. Antônio Buyawaçu, navegando pelo rio Negro com a sua família, foi atraído quando passava pelo poço do Humaitá. Ele me relatou que a sua canoa estava sendo sugada para o fundo e concluiu que era a força das raias que queriam levar seu neto recém-nascido para o fundo. 
Todos os dias, ao entardecer, aparece uma grande e iluminada embarcação que desaparece ao alvorecer. Um deles navega em direção ao rio Negro até a Ilha Nova Vida, regressando posteriormente para o rio Preto. Tal fato foi atestado por outros Baré habitantes de outras comunidades no rio Negro, que dão outra versão para tal acontecimento. Um exemplo desse fato é narrado por moradores da comunidade de Romão no rio Araçá, os quais contam que essa embarcação parte da antiga comunidade de Pai Raimundo ${ }^{12}$ e se direciona para a foz do rio Aracá, considerado o local de maior profundidade no médio curso do rio Negro, chegando atingir aproximadamente trinta e dois metros de profundidade. Os mais jovens, céticos, fazem críticas severas aos mais idosos e dizem que o que os velhos olham é a cobra-grande e não embarcações iluminadas.

Os encantados não querem somente se vingar dos humanos, como foi enfatizado acima, eles desejam também manter convívio com os moradores das comunidades, bem como realizar trocas e é nesse intuito que os encantados se transformam em humanos para saciar seu quase-desejo e se possível levar algum humano querido para o mundo de baixo. Alguns humanos já foram arrebatados pelos encantados e levados para conhecer sua cidade do fundo. Essas viagens são paradoxais e podem ser fatais, pois às vezes não têm volta, ou, quando a pessoa consegue regressar para a comunidade de parentes, passa a agir de maneira diferente, como apresentado na narrativa denominada akwena pirá contada pelo Antônio Buyawaçu no ano de 2013.

A comunidade enfrentava escassez de alimentos, sobretudo de peixes, pois o rio estava cheio, as roças não estavam maduras e as caças se afugentaram. As crianças estavam tristes, os velhos que ainda não recebiam aposentadoria não podiam fazer nada para trazer alimentos para a comunidade. Os rapazes acusavam uns aos outros de panema [sem sorte nas caças e nas pescarias]. Então, poucos se arriscavam a sair para pescar. Mas havia dois rapazes insistentes que mesmo sabendo que estavam com panema não deixavam de ir pescar todos os dias. Durante uma semana, rio abaixo e rio acima, eles andavam pelejando com a pescaria, mas voltavam sempre com a canoa vazia. Eles usavam o espinhel, a malhadeira, o caniço, a linha, a zagaia, mas nada de peixe. Um dia, um dos rapazes resolver ir sozinho pescar. Quando subiu o rio encontrou uma canoa descendo o rio de bubulha ${ }^{13}$ e dentro dela havia um pescador que não era pessoa conhecida da região. Essa canoa era a cobra-grande. $O$ rapaz perguntou para o homem aonde ele havia malhado tanto peixe. O homem respondeu. - No lago dos meus parentes. Então o homem perguntou para o rapaz: você que ir lá? Eu posso te ensinar os furos para chegar até lá. aí você pode malhar peixe o suficiente e levar para os teus companheiros, mas depois você me convida para uma festa na sua comunidade. Eu vou aparecer a qualquer momento. O rapaz concordou e acompanhou o homem [gente-peixe] e, em questão de segundos, ele adormeceu e sentiu seu corpo todo melado por uma essência gosmenta de cheiro de peixe, que é o "Akwen pira" - perfume dos peixes. Quando o rapaz acordou, estava em um lugar que não conhecia, as coisas pareciam estranhas, havia espécies de peixe que ele desconhecia que não eram do rio Negro, mas falavam e ele entendia. O tempo lá era diferente do nosso, enquanto aqui era dia, lá era noite, só que a noite era maior que o dia. Os peixes gostam muito de andar durante a noite, por isso a noite é maior que o dia. Lá na morada da gente-do-fundo parecia que todos estavam bem, faziam festas, havia muita alimentação. O rapaz ficou o tempo todo como se estivesse sonolento. Ele ficou deitado em cima de uma laje lisa e via um monte de peixes que falavam em sua volta, ele entendia muitas palavras, mas não era português nem o nheengatu. Tinha um peixe que ficava chupando coisas do corpo do rapaz, coisa que os "estragara”, uma espécie de sacaca. E o tempo todos os peixes passavam no corpo do rapaz uma essência, o perfume dos peixes para que ele não acordasse, porque era aquele perfume que garantia sua permanência lá no fundo. Então o peixe chefe chupou o

${ }_{12}$ Pai Raimundo era uma das comunidades mais antigas do rio Aracá. Foi abandonada devido às pessoas acreditarem que abaixo da comunidade existia uma cidade encantada. Atualmente, só existem ruínas no espaço onde se encontrava a comunidade. Sobre a comunidade de Pai Raimundo ver (BARRAS et al., 2013)

${ }_{13}$ É uma expressão amazonense que significa que uma canoa ou uma pessoa desprende-se e desce correnteza abaixo boiando à deriva. 
rapaz e, depois de terminar o serviço, mandou seus companheiros peixes que o levassem de volta para sua canoa. Quando o rapaz acordou, estava todo melado de uma gosma parecida com o sêmen dos peixes. Ele lembrava somente de poucas coisas que haviam acontecido, porém lembrava que um homem havia passado por ele em uma canoa cheia de peixes. Ficou matutando, e resolveu entrar em um lago onde as pessoas não costumavam colocar malhadeira, porque havia uma população muito grande de yacareassú [uma espécie de boto] que rasgavam as malhadeiras e comiam os peixes. Mesmo sabendo do risco que corria, esticou a malhadeira e ficou esperando do outro lado do rio, se limpando do odor de peixe que impregnava seu corpo. Não demorou muito e o rapaz foi tirar a malhadeira. Estava cheia de peixes, era pacu, matrinchã, aracu, corvina, só peixe de carne boa. Quando ele voltou para a comunidade, distribuiu peixe para sua parentela e contou o que havia acontecido. Ele disse: a gente-do-fundo afastou a panema do meu corpo. O rapaz deu peixes para as famílias. Agora nós temos que nos juntar para fazer uma festa para o homem [gentepeixe] que eu encontrei no rio. Ele deve aparecer a qualquer hora por aqui. (Antônio Buyawaçu Baré, Campinas do Rio Preto, 10 de novembro de 2013)

Observa-se um conjunto de elementos que podem ser pensados enquanto trocas reciprocas entre diferentes gentes. A narrativa confirma a plasticidade das relações de vizinhança no rio Negro e indica as especificidades do agenciamento. Elas evocam questões que dizem respeito à potencialidade de especialistas, como benzedeiras/rezadores, sacacas e, principalmente os xamãs, que possuem capacidades específicas para adentrar em outros mundos. Embora o trânsito ou a mobilidade entre mundos sejam possíveis, há rígidas orientações e prerrogativas que habilitam os xamãs a transitar com segurança no mundo-do-fundo. Eles podem estabelecer relações, firmar acordos, participar de cerimoniais de socialidades e realizar alianças políticas e matrimoniais com essas outras gentes, coadunando para uma espécie de "diplomacia cósmica14".

\section{Visita dos encantados a cidade-de-cima}

Diferentemente dos humanos, que precisam dos xamãs para percorrer o cosmos, ou "mundo-outros" como denomina BIDOU (1983), os encantados, de maneira geral, frequentemente visitam a cidade-de-cima com muita facilidade. Eles se apresentam em diversas formas, metamorfoseados em botos, sucuriju, sapos, raias, patrão, pessoas idosas, entre outros. Também existem os encantados que vivem nas florestas, muitos deles são confundidos com gente de encantes, por exemplo, o niracanga ${ }^{15}$, mapinguari, o mati e o curupira, estes considerados incorporações de poderosos xamãs já falecidos. Também existem árvores que se transformam em encantados para agredir pescadores e caçadores. Além destes, existem os encantados de possessão que incorporam em uma pessoa vulnerável ${ }^{16}$, às vezes conduzindo-as a viver em seu mundo, bem como para servir de guia espiritual no mundo terreno e durante as viagens ao cosmos.

Os encantados são considerados seres paradoxais, às vezes perigosos, vingativos, invejosos e amoerante ${ }^{17}$, mas também amistosos e necessários. Sendo assim, as visitas que fazem ao mundo dos humanos têm vários propósitos, entre eles carregar pessoas escolhidas para o seu mundo, vingar-se de pessoas que maltrataram os habitantes do mundo-de-baixo, bem como a disseminação de doenças com o intuito de atrair os xamãs para suas viagens cósmicas, deixando a comunidade carente do seu principal mediador espiritual. Isso corrobora com a observação de Viveiros de Castro (2018: 63), que assevera que “apenas os xamãs,

\footnotetext{
${ }^{14}$ Sobre Diplomacia cósmica ver (STENGERS, 2018)

15 Uma espécie de bicho cujo formato do corpo é peludo musculoso com duas cabeças.

${ }^{16}$ Aquelas menstruadas que quebraram as regras e foram tomar banho no rio no final da tarde, pessoas que quando pequenas não passaram pelos benzimentos dos sacacas e, portanto, ficam com o corpo aberto, pessoas que ingerem alimentos perigosos sem antes terem sido benzidos, entre outras.

${ }_{17}$ Categoria nativa que significa pessoa que deseja algo que não é seu ou o desejo do quase-nada no sentido deleuziano.
} 
gozam de uma sorte de dupla cidadania no que concerne à espécie e à condição de vivo ou morto: podem fazê-las comunicar, e isso, sob condições especiais e controladas".

As visitas dos encantados ao mundo dos humanos demonstram ambiguidades, pois eles também procuram manter relações afetivas, quando passam a seduzir homens, mulheres e crianças. A sedução de homens, mulheres e crianças por encantado é muito recorrente nas narrativas das populações indígenas no rio Negro, principalmente entre os Baré, ainda que afirmem que os encantados vêm se afastando dos humanos por não suportarem a zoada produzida pelos motores de popa das embarcações dos turistas e o barulho estrondeantes dos motores tipos rabetas das canoas pequenas dos moradores locais. Esses ruídos lhes causam doenças e, por isso, estão deixando de se relacionar com tanta frequência com os povos de cima. No entanto, estariam se tornando mais e mais agressivos:

Os bichos-do-fundo têm hora que eles somem, custam aparecer, deixam de mexer com gente que mora nas comunidade, gente de cidade, mas quando eles atacam é pra valer, eles se tornaram mais agressivos, mais irritados com a zoada de motor de popa e todo esse tipo de coisas barulhentas. Os bichos-do-fundo gostam de silêncio, gostam de águas calmas, gostam de famílias pequenas. Eles estão mais presentes nos igarapés, nos piaçabais, lá tem muito. Nos piaçabais os pobres dos fregueses penam nas mãos desses bichos. Na mata grande você enxerga onça como se fosse gente, você escuta o assobio de niracanga, você é atacado pelo mati. Antigamente aqui na beira da comunidade a gente via muito dessas coisas, era como bons vizinhos. Os bichosdo-fundo não são tolos não, eles sabem que as coisas estão mudando e vão procurando as coisas que se parecem com a vida dos antigos. Sabe lá porque eles fazem isso. (Antônio Buyawaçu, comunidade de Campinas do Rio Preto, julho de 2014)

Para os Baré do rio Preto, os bichos-do-fundo demonstram consciência quanto às mudanças que estão acontecendo na vizinhança dos seus mundos, e essas mudanças despertam comportamentos que nem propriamente os humanos mais especializados, como os xamãs e rezadores não estão conseguindo entender, enxergar e decifrar. No entanto, Antônio Buyawaçu faz uma analogia pertinente para pensar essa situação:

\begin{abstract}
As coisas não mudam muito, apenas se apresentam com outras sombras. É como as nuvens que se transformam em gente, em bichos, peixes, anjos, santos, cobra-grande, tudo que você pensa aparece nas nuvens. mas as nuvens sempre vão ser nuvens. Nós acompanhamos o movimento deles, nós somos gentes e as nuvens são nuvens. Os padres, os militares e os regatões invadiram o rio Negro, trouxeram doenças, escravizaram nossos parentes e promoveram guerras contra as nossas línguas e a nossas atividades. Os mais velhos ficaram tristes, alguns morreram porque não conseguiam conviver com outros sons e outras sombras. Os bichos estão passando tudo que os antigos passaram, do mesmo jeito. Antigamente, os bichos-do-fundo tinham mais simpatia com todos nós, porque eles ajudavam os mais velhos a se esconder da cambada de "gente" que andavam por aqui matando e escravizado índio e roubando nossas plantas. Agora tudo que não presta está chegando nos mundos mais difíceis de se chegar. Bateram na ponta final no mundo do [bichos-do-fundo]. São poucas as pessoas que sabem caminhar por lá. O cheiro forte da gasolina, o som dos CDs. [eletrônicos] parece que invadem com mais facilidade, como um desenho de uma nuvem que ninguém sabe mais o que é. Isso incomoda bastante todas as gentes daqui do rio. Sabe lá como esses bichos estão sofrendo? E a gente sofre com eles também, por aqui no rio Negro eles estão desde de antes e a gente não pensa sem eles. A gente sofre também, porque tudo está em nossas vidas em nossos pensamentos junto deles. (Antônio Buyawaçu, Campina do Rio Preto, agosto de 2014)
\end{abstract}

Há uma motivação unidirecional que impulsiona a fúria dos encantados? Os processos de socialidades e afinidade com os vizinhos-do-fundo estariam ruindo? Os moradores do "fundo" estão se tornando inimigos e perdendo o senso da relação amistosa? Para os Baré do rio Preto, os encantados que chegam a visitar o 
mundo-de-cima trazem consigo propósitos diferentes, principalmente os encantados vingadores e os amoerantes, que cobiçam a sombra das pessoas, em especial de certos tipos de "gente" que faltam na cidade-do-fundo, por exemplo, mulheres e crianças consideradas portadoras de dons especiais e que são diferentes dos padrões locais. Os bichos-do-fundo são dotados de poder e entendem que todos os humanos e todas os tipos de "gente" apresentam paradoxos e, esses paradoxos, impulsionam o desejo ${ }^{18}$ do "quase-nada". Por quê? Porque eles têm tudo e ao mesmo tempo não possuem nada, mas são motivados a manter convivialidade e criar ou recriar os laços de afinidade, compartilhando felicidade, sofrimento, prazer, fúria, mas também amizade que pode ou não gerar inimizade. Eles consensualizam a necessidade da convivialidade que passa pela questão de desejar o "quase-nada” e do estabelecimento de socialidades interespecíficas:

\begin{abstract}
Esses bichos têm tudo, mas eles querem os nossos práticos, nossas mulheres, nossas crianças e aquelas pessoas sabidas que são diferentes, sabe? Eu nunca duvidei que não é só mulher e crianças que eles querem. Veja! Meu sogro se amancebou com uma mulher deles. O que aconteceu? Ele viveu feliz e a comunidade de Campina nunca foi para o fundo. Pode chover dias e noites, aqui sempre vai ficar no seco. Isso é beneficio? É, é sim. Gente tem que saber onde pisar e saber o que falar e entender tudo direitinho. A visão tem que tá muito apurada, sabe? Meu finado sogro foi homem feliz. Duas mulheres: uma na comunidade e outra no fundo. Ele manteve sua honra com os bichos. Depois de morte, ainda tem deles que visitam a gente. Eles protegem sabe, mas também a vontade deles de malinar é sempre, as vezes só mesmo para mexer pra gente saber que eles estão sempre por aqui. Eles não deixam de mexer com a gente e o finado meu sogro sabia disso. (Antônio Buyawaçu, Campina do Rio Preto, agosto de 2014)
\end{abstract}

Os indígenas rionegrinos confirmam, em sua maioria, que a cidade-de-baixo se assemelha ao mundo-de-cima, o que faz com que os encantados não necessitem de coisas materiais e ou artefatos do mundo-de-cima; todavia faltam no mundo-do-fundo pessoas iguais aos Baré, aos Tuyuka, aos Tukano e os bons xamãs que preservam dons específicos, por isso, a necessidade de convivialidade e o estabelecimento de socialidades interespecíficas, como ocorreu com o líder baré e fundador da comunidade de Campina do Rio Preto, Caetano de Jesus, que casou com uma mulher da cidade-do-fundo estabelecendo uma espécie de "poligamia encantada" e outros acordos intramundanos ${ }^{19}$. Nesse sentido, gente-de-cima ou os humanos indígenas possuem algo a mais que os distinguem dos outros tipos de gente.

\title{
Perspectivismo e saberes locais: socialidades interespecíficas e vizinhança
}

As relações entre gente-de-cima (humanos e outros seres terranos) e gentedo-fundo (extra-humanos, encantados, encantes, etc.) assentam-se em movimentos paradoxais contínuos e simétricos necessários, como guerra-paz; equilíbrio-desequilíbrio, amigos-inimigos, presa-predador, patrão-freguês, iguais-diferentes, desejo-repulsão, dom-contra/dom entre outros que condicionam a per-

\footnotetext{
${ }^{18}$ Nossa reflexão se aproxima parcialmente das reflexões de SCHOPENHAUER (2005), quando considera que o desejo é simplesmente a consequência necessária da impressão atual, seja quando esta derive da excitação externa, seja quando derive da disposição interna transitória. Não obstante, o desejo do quase-nada é uma reflexão que imprimo a partir do desejo dos encantados, pois estes possuem tudo, porém ao mesmo tempo não possuem nada, quando se trata de algo de ultra necessidade da ausência em seus mundos, por exemplo, o corpo baré.
} 
meabilidade entre os mundos inextrincavelmente emaranhados. Esse fundamento corrobora para a nossa abordagem perspectivista relacionada às socialidades e vizinhanças entre "gentes" no noroeste amazônico.

No entanto, cabe ressaltar que o perspectivismo ameríndio não corrobora com a ideia de que os animais são "no fundo", semelhante aos humanos, mas sim, como assevera Viveiros de Castro (2002) de que eles, como os humanos, são outra coisa, em outras palavras, são diferentes de si na morfologia corpórea ${ }^{20}$. A morfologia corpórea tanto dos humanos quanto de outras gentes possibilita o trânsito e conduz movimentos contínuos de antropomorfização. Esse movimento atrelado a antropomorfização corpórea é vital para o estabelecimento de socialidades interespecíficas ${ }^{21}$. Por exemplo, o boto que se antropomorfiza para seduzir mulheres, assim como indígenas que se transfiguram em gente-onça ou caricawara ${ }^{22}$ para socialização interespecífica xamânica. Raias (arraias) que se pintam de mulheres adocicadas para atrair homens indígenas para o coito no sentido de provocar alianças polígamas consubstanciadas. Esses exemplos convergem com algumas concepções do perspectivismo ameríndio, quando considera as diferenças substanciais como capazes de intensificar o trânsito entre humanos e não-humanos no interior de cada existente 23.

Todos os seres potenciais (humanos e extra-humanos) que estabelecem socialidades no contexto no rio Negro são vistos como entidades complexas com estrutura ontológica de dupla face, uma visível e outra invisível, corroborando com a propositiva perspectivista relacionadas aos modos pronominais do reflexivo e do recíproco que assenta nos modos relacionais do intencional e do coletivo, ou seja, das trocas de perspectivas ou não, o "Eu" (self) e o "Outro".

Neste sentido, visualiza-se que as socialidades interespecíficas se constituem entre vizinhanças adjacentes no sentido de coabitação humana, onde além de compartilhar substâncias que intensifica o trânsito, compartilham perspectivas, conhecimentos mútuos, mantendo relações tangíveis e não tangíveis, ou seja, os humanos, gente-do-fundo e outras gentes se percebem entre si, evidenciando que cada um existe a sua maneira.

Tudo indica que o trânsito intramundano não tem a intenção das "gentes" se apossar das coisas dos outros, tampouco de permanecer no mundo alheio e se apropriar de coisas tangíveis, mas somente "curiar" e depois retornar para o seu mundo incólume. É como se fosse uma ação do desejo do quase-nada no sentido empregado por Gilles Deleuze, do querer e da vontade intencional, que muito se assemelha às reflexões aristotélicas ${ }^{24}$, quando elenca que desejamos porque existem outros, a vida dos outros, existe a relação dos outros com o mundo dos outros e esse desejo do quase-nada sustenta e preserva as socialidades interespecíficas.

Nossa contribuição para pensar vizinhança e socialidades interespecíficas no contexto do noroeste amazônico coaduna às filosofias locais que estabelecem conexões com alguns pressupostos do perspectivismo ameríndio. Todavia, o emaranhado de caminhos foi desenhado para visualizarmos as cidades encantadas, suas gentes e a necessidade de estabelecer socialidades interespecíficas pode ser

\footnotetext{
${ }^{20}$ Para VIVEIROS DE CASTRO (2002), uma perspectiva não é uma representação, pois as representações são propriedades do espírito, mas o ponto de vista está no corpo.

$21 \mathrm{O}$ animismo estabelece uma semelhança substancial ou analógica entre animais e humanos, enquanto o totemismo considera uma semelhança formal ou homológica entre diferenças intra-humanas e diferenças interespecíficas. Ver Viveiros de Castro (2018; 2002; 1996).

${ }^{22}$ Sobre gente-onça ou caricawara no noroeste amazônico, ver NASCIMENTO (2017: 212).

23 Para essa discussão, ver VIVEIROS DE CASTRO (2018: 61).

24 “(...) a condição básica é que, ao eleger o outro e suas qualidades como objeto de desejo, este outro não pode estar longe do seu sentimento, mas não do seu pensamento como existente. Eu não desejo alguém inatacável, alguém que esteja fora do meu campo de percepção”. (ARISTÓTELES, 2000: 69)
} 
resumido numa ideia-chave do meu principal interlocutor, Antônio Buyawaçu, que corrobora com as nuances elencadas nas entrelinhas desse texto:

\begin{abstract}
Nada no rio Negro se pode fazer sozinho. A casa não é casa sem outras gentes a visitar; comunidade que não recebe visita de boto, de cobra-grande não pode ser comunidade; pescador que nunca encontrou e namorou com outros bichos não pode ser pescador. Tudo que aparece é porque nós e eles precisamos. Ninguém malina ninguém se não for para o agrado. No rio têm outras moradas, outras gentes que à luz não se pode enxergar. (Antônio Buyawaçu, Campina do Rio Preto, agosto de 2014)
\end{abstract}

\title{
Considerações
}

No noroeste amazônico a plasticidade das relações de vizinhança é bem nítida e se configura em fronteiras permeáveis relacionais abrangentes que vai além do campo da natureza e que perpassa pelo multinaturalismo. As narrativas que potencializam visões de outros mundos e de outras naturezas, por exemplo, as cidades encantadas e outras gentes indicam caminhos múltiplos que fazem conexões com mundos múltiplos inextrincavelmente imbricados com sujeitos intencionais de desejo ou desejo de quase-nada.

A ideia-chave do meu principal interlocutor revela a necessidade da coadunação entre pensamentos, mundos e sujeitos. O que se almeja dessa troca entre mundos? Muitas respostas podem ser possíveis, porém sem cair no reducionismo, procuramos deixar as narrativas indicar as expressões imaginativas do mundo antigo, pois o que se observa como recorrente são as necessidades que retrocedem aos tempos primordiais, quando o demiurgo deixou muitas coisas do cosmos incompletas e por causa dessa incompletude, "gentes" (humanos e extrahumanos) vivem especulando sobre outros espaços e tempos específicos, além de buscar o complemento uns com os outros na conexão intramundana e no pensamento do desejo do quase-nada que foi se instruindo entre todas as "gentes" do rio, criando sujeitos com habilidades e visões específicas, por exemplo, os xamãs, os rezadores e os sacacas, que receberam poderes especiais que lhes impulsionam a estabelecer socialidades interespecíficas, assim como se tornaram responsáveis em estabelecer agenciamentos que conduzem relações múltiplas numa perspectiva da cosmopolítica.

No noroeste amazônico, os sujeitos se realizam no coletivo e na busca de alianças assentadas em bases sociocosmológicas comuns. Tudo indica, que os indígenas rionegrinos estão felizes quando compartilham com outras gentes das quais eles convivem desde os tempos dos demiurgos. Desde então, se movimentam nas correntes da necessidade, do desejo, promovendo reciprocidades na esfera de uma "democracia cósmica", parafraseando a filósofa Isabelle STENGERS (2015). Nesse contexto, todos os lugares no rio Negro são considerados como de bom-viver, onde "gentes" de suas maneiras podem estabelecer socialidades, porém, as socialidades interespecíficas somente foram concebidas àqueles, que mesmo na incompletude dos poderes dos criadores carregam consigo desenhos que estão impingidos no pensamento e que são capazes de responder por toda situação. 


\section{Referências}

ANDRELLO, Geraldo. "Aún mi cuerpo aloja una lanza de los peces": troca e predação no noroeste amazônico. Anuário Antropológico, 42 (1): 229-248, 2017.

ANDRELLO, Geraldo. Escravos, descidos e civilizados: índios e brancos na história do rio Negro. Revista de Estudos Amazônicos, V (1): 107-144, 2010.

APPADURAI, Arjun. A vida social das coisas. As mercadorias sob uma perspectiva cultural. Niterói: Editora da UFF, 2008.

ARHEM, Kaj. Ecocosmologia Y Chamanismo em el Amazonas: variaciones sobre un tema. Revista Colombiana de Antropologia, 37 (1), 2001.

ARISTÓTELES. Relatos das paixões. São Paulo: Martins Fontes, 2000.

BARRA, Camila et al. Barcelos indígenas e ribeirinha. Um perfil socioambiental. São Paulo: Instituto Socioambiental, 2013.

BARROS, Lilian Cristina S. O Kapiwayá e seu lugar no universo músico-coreográfico-ritual em um clã Desana, Alto Rio Negro, Amazonas. Boletim do Museu Paraense Emílio Goeldi, 7 (2): 509-523, 2012.

BIDOU, Patrice. Le travail du chamane: essai sur la personne du chamane dans une société amazonienne, les Tatuyo du Pirá-Paraná, Vaupés, Colombia. L'Homme, 23 (1): 4-53, 1983.

IUBEL. Aline Fonseca. Estados em transformação: movimento indígena e políticas no Alto Rio Negro (noroeste Amazônico). São Carlos: Tese de doutorado, PPGAS-UFSCar, 2014.

IUBEL, Aline Fonseca. Relações exteriores nas políticas indígenas em São Gabriel da Cachoeira: indigenização da prefeitura e incorporação de alteridade. Revista de Antropologia, 61 (1): 360-380, 2018.

LASMAR, Cristiane. De volta ao logo do leite. Gênero e transformação no Alto Tiquié. São Paulo/Rio de Janeiro: Editora da UNESP, ISA, NUTI, 2005.

MAIA FIGUEIREDO, Paulo R. Desiquilibrando o convencional: estática e ritual com os Baré do Alto Rio Negro (AM). Tese de doutorado, PPGAS-UFRJ, Museu Nacional, Rio de Janeiro, 2009.

MEIRA, Márcio. A persistência do Aviamento: colonialismo e história indígena no noroeste Amazônico. Tese de doutoramento, Universidade Estadual do Rio de Janeiro, PPGMS, 2017.

MEIRA, Márcio. O tempo dos patrões. Extrativismo da piaçava entre os índios do rio Xié (Alto rio Negro). Dissertação de mestrado, UNICAMP. 1993.

NASCIMENTO, L. A. S. Patrões, fregueses e os donos: economia e xamanismo no médio rio Negro. São Carlos: Tese de doutorado, PPGAS, UFSCar, 2017.

NASCIMENTO, L. A. S. Relatório de fundamentação antropológica das comunidades habitantes dos rios Padauiri e Preto no Médio Rio Negro. Mimeografado, Brasília, Funai-Unesco, CGID, 2012. 
OVERING, Joanna. Elogio do cotidiano: a confiança e a arte da vida social em uma comunidade amazônica. Mana 5(1): 81-107, 1999.

REICHEL-DOLMATOFF, Gerardo. Desana: Simbolismo de los Indios Tucano del Vaupés. Bogotá: Universidad de Los Andes, 1990.

SAMPAIO, Patrícia M. "Aleivosos e rebeldes: lideranças indígenas no rio Negro no século XVIII”. In: ALMEIDA, A.; FARIAS JR., E. (org.). Mobilizações étnicas e transformações sociais no Rio Negro Manaus: UEA edições, 2010.

SCHOPENHAEUR, Arthur. O mundo como vontade e representação. Livro I. Tradução Jair Barboza. São Paulo: Editora da Unesp, 2005.

SOARES, R. Martelli. Das comunidades à federação: associações indígenas do Alto Rio Negro. Dissertação de mestrado, PPGAS-USP, 2012.

STENGERS, Isabelle. A proposição cosmológica. Revista do Instituto de Estudos Brasileiro, 1 (69): 442-464, 2018.

STENGERS, Isabelle. No tempo das catástrofes. Resistir à barbárie que se aproxima. São Paulo: CosacNaify, 2015.

VIVEIROS DE CASTRO, Eduardo. A inconstância da alma selvagem. São Paulo: CosacNaify, 2002.

VIVEIROS DE CASTRO, Eduardo. Metáforas canibais. Elementos para uma antropologia pós-estrutural. São Paulo: Ubu Editora, 2018.

VIVEIROS DE CASTRO, Eduardo. Os Pronomes Cosmológicos e o Perspectivismo Ameríndio. Mana, 2 (2): 115-144, 1996.

WRIGHT, Robin M. "História Indígena do Noroeste da Amazônia: Hipóteses, Questões e Perspectivas”. In: CUNHA, Manuela Carneiro (org.). História dos Índios no Brasil. São Paulo: Companhia das Letras/Secretaria Municipal de Cultura/FAPESP, 1992.

WRIGHT, R. "O tempo de Sophie: história e cosmologia da conversão baniwa". In: WRIGHT, R. (ed.). Transformando os deuses: os múltiplos sentidos da conversão entre os povos indígenas no Brasil. Campinas: Editora da Unicamp, 1999. pp. $155^{-215}$. 

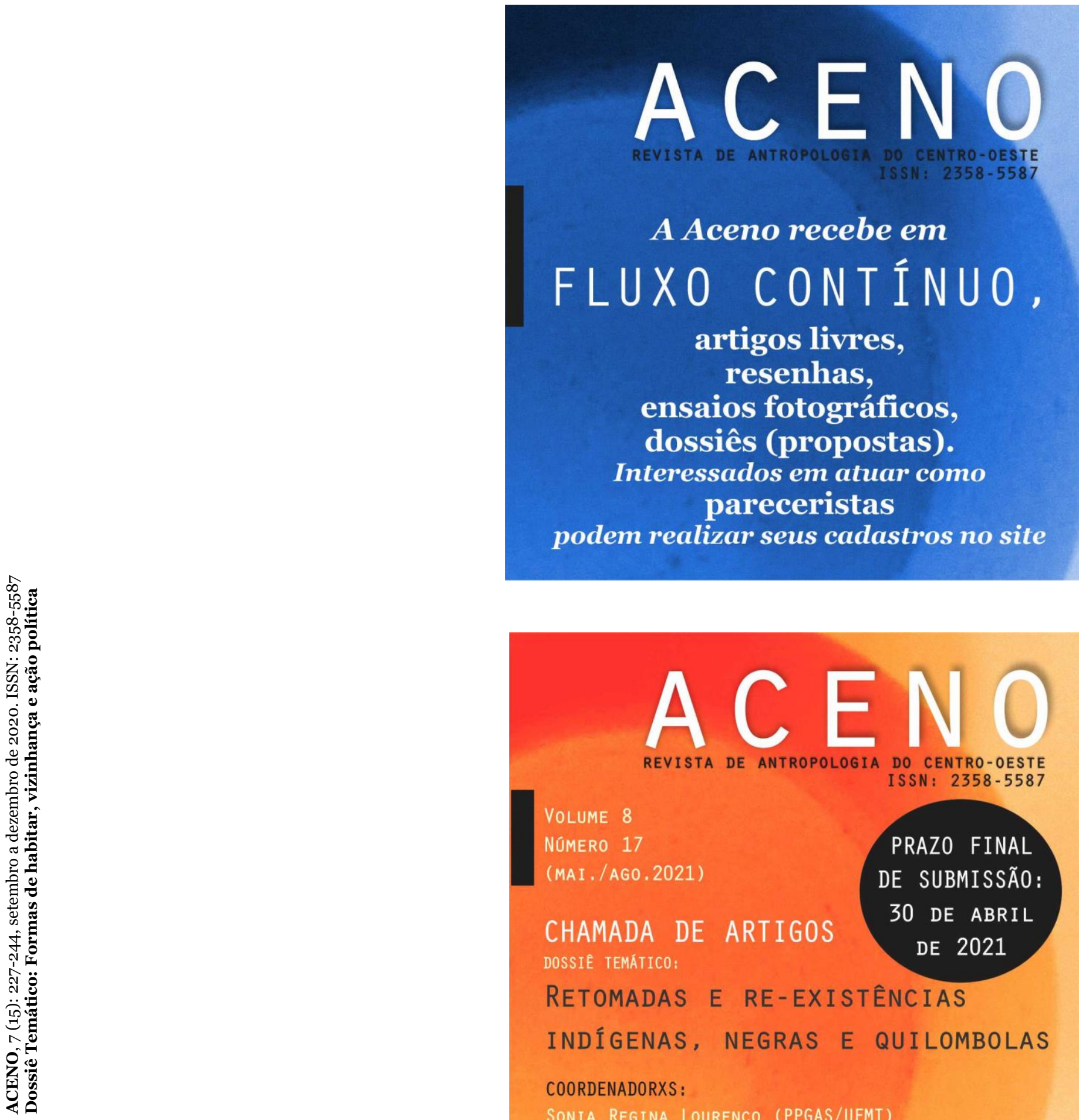

VOLUME 8

NÚMERO 17

PRAZO FINAL

(MAI ./AG0, 2021)

CHAMADA DE ARTIGOS DOSSIE TEMÁTICO: DE SUBMISSÃO:

30 DE ABRIL

RETOMADAS E RE-EXISTÊNCIAS

INDÍGENAS, NEGRAS E QUILOMBOLAS

COORDENADORXS:

SONIA REGINA LOURENÇO (PPGAS/UFMT)

CAUÊ FRAGA MACHADO (NUPACS/UFRGS)

SANDRO JOSE DA SILVA (PGCS/UFES) 